\title{
Jevons' Paradox And The Economic Implications For Europe
}

\author{
John M. Polimeni, (E-mail: polimenj@acp.edu), Albany College of Pharmacy
}

\begin{abstract}
Energy consumption has increased considerably in the past two hundred years despite more efficient technology advancements. This positive correlation between increased energy consumption and increased efficiency is known as Jevons' Paradox. Increased energy consumption should be of concern because all the inputs to economic production come from the environment and the consumption of resources from the ecosystem will cause an economic slowdown. Additionally, the consumption of natural resources to provide energy is an irreversible process, worsening the human condition instead of improving human welfare. Therefore, sustainable development policies need to be considered to end the continued excess consumption, beyond sustainable levels, of natural resources and the potential resulting conflicts. To design environmentally sustainable policies, the effect of economic activity, of resource utilization, and increased efficiency must be understood. In this paper, we attempt to illustrate how energy consumption alters the natural state of the economy and the environment. Further, using energy data from the Energy Information Administration we develop models that provide empirical support that Jevons' Paradox may exist on a macro level for the countries of Europe. Specifically, eighteen European countries are examined. Finally, the resulting policy implications and the applications for an ecological economic approach are explored.
\end{abstract}

\section{INTRODUCTION}

tandard economic theory states that energy prices will increase as the supply of natural resources used to produce energy, such as oil and natural gas, decreases. These higher energy prices will stimulate investment into the research and development of new technologies that will conclude in energy conservation. In the long run, these technologies will lead to lower energy intensities of households and firms (Velthuijsen and Worrell 2002). The end result will be an improvement in environmental quality, through a reduction in the consumption of natural resources, with a minimal effect on the economy (Foster 2000). Policymakers around the world have developed national and regional strategies that focus on technology to reduce energy consumption, which contributes to environmental problems. However, is new energy efficient technology a solution to reduce energy consumption, and thus the depletion of natural resources that are needed to produce energy as many stakeholders believe? In this paper we argue that energy efficiency improvements will not lead to decreased energy consumption and, therefore, improved environmental conditions. Rather, we contend that increased energy efficiency actually results in the increased demand and use of energy. Thus, technological improvements that result in improvements in energy efficiency will not result in decreased energy consumption or the resultant environmental damage as has been promised. This argument, that improvements in energy efficiency lead to increased energy consumption, is known as 'Jevons' Paradox'.

Jevons found that increased demand for a resource due to efficiency will occur because of a rising level of possible production (Jevons 1865, 1965). In chapter seven, entitled "Of the Economy of Fuel," in The Coal Question, Jevons detailed his ideas using the history of the steam engine to illustrate his point of how each improvement led to increases in the scale of production and in the demand for coal. Jevons wrote, "Every such improvement of the engine, when affected, does but accelerate anew the consumption of coal. Every branch of manufacture receives a fresh impulse - hand labor is still further replaced by mechanical labor" (Jevons 1865, 
1965). Technological improvements are typically energy-using and labor-saving through the use of more powerful energy converters (Georgescu-Roegen 1975).

Research studies of Jevons' paradox have examined the residential sector of individual countries (Haas and Biermeyr 2000; Milne and Boardman 2000; Berkhaut, Muskens, and Velthausen 2000; Roy 2000; Scott 1980), used production functions to examine how industries consume energy when energy efficiency increases (Saunders 2000a; Jaccard and Battaille 2000), examined the determinants of energy use (Schipper et al. 2001) and other studies project how the paradox might impact future energy consumption (Birol and Keppler 2000; Laitner 2000). For the purposes of this paper, the aforementioned papers are considered micro level studies, focusing on specific sectors of the economy (i.e., the energy sector) and/or consumption activities (i.e., refrigerators, cars, etc.). This paper takes a different approach, examining the energy consumption/energy efficiency relationship on a macro (country and multi-country) level. Empirical analysis of eighteen European Union countries is presented to show that Jevons' paradox may exist on a macro level for total primary energy consumption. A systematic approach is used to determine which factors, such as population, drive the paradox. Analysis of this kind is important because policymakers are relying on technology to counter the effects of increased energy demand, and hence, increased consumption of natural resources. There will be no discussion as to the specific regional or country-level reasons for either the possible existence or lack of existence for Jevons' paradox as that would require a much deeper examination and will be the focus of further research on the subject. The following sections present a discussion of Jevons' paradox and examine the relevant literature on the subject, Section 3 describes the data and the various models that are used in the paper, Section 4 presents the results of the models, and lastly Section 5 discusses the implications of the findings and concludes the paper.

\section{JEVONS' PARADOX: THE LITERATURE}

As stated previously, Jevons' paradox arises when efficiency increases in using a resource leads to an increase, rather than a reduction, in the consumption of that resource in the medium to long-run (Giampietro and Mayumi 2005). In 1865, when William Stanley Jevons first made this claim in his book The Coal Question he was referring explicitly to coal consumption and other fossil energy resources. Specifically, he argued that improved coal efficiency leads to increased coal consumption because of profitability, new inventions and uses, and consumer behavior (Chapters VI, VII, IX, and X). Jevons maintained that the quantity of coal is not as important as the rate at which consumption of coal increases (p. 25, 34-36). This claim holds for other resources as well, particularly energy consumption.

With this theory one can consider resource consumption, proportional to environmental impact (I), to be equal to the product of population (P), affluence (A), and technology (T) (Ehrlich and Ehrlich 1991, 1992; Ehrlich and Holdren 1971; Alcott 2005). This equation, first recognized by Jevons (1865, 1965), implies that environmental impact will increase as population, affluence (consumption), and/or technology increase. Jevons' found that economic growth will lead to increased population and, therefore, an increase in the demand for coal. For the purposes of this paper resource consumption is defined as the exhaustion of resources (Boulding 1949; Princen 1999). Following the second law of thermodynamics, any consumption of a resource will lead to a waste product; for energy resources this would typically be in the form of pollution, such as $\mathrm{CO}_{2}$.

Therefore, Jevons' paradox has important implications, not only for energy consumption but also for environmental conditions. Reducing resource consumption through increased energy efficiency is good for complex systems, such as the environment, because less pollution, in the form of waste product, is released. Energy efficiency increases reduce the consumption of inputs, which in turn reduces the cost of production. As the cost of production declines, demand (i.e. consumption) increases. However, given the opportunity, humans consume more, resulting in the paradox.

Many contemporary examples of Jevons' paradox and the process described above, sometimes called the rebound effect or the paradox of prevention, exist. For instance, although the efficiency of food production per hectare has doubled the last half century the hunger problem has become worse because of an increase in population (Giampietro 1994). The creation or expansion of new roads has not relieved traffic congestion because they have 
encouraged the increased use of cars (Newman 1991). Traffic congestion was further worsened by higher oil prices which resulted in more energy-efficient automobiles, which lead to increased levels of driving activity (Cherfas 1991). Now, bigger and more petroleum consuming vehicles have become very popular (Mayumi 2001). A final example would be refrigerators, where technological improvements have led to bigger refrigerators (Khazzoom 1987; Foster 2000). Thus, as a resource becomes more efficient to use, it becomes less expensive allowing more of the resource to be consumed with the same budget constraint.

However, the increase in demand for a resource is not strictly confined to a products' own end-use, but also for other end-uses because they compete for the same overall budget (Khazzoom 1980). Therefore, there is not only a direct micro rebound effect that exists, but also an indirect macro rebound. The macro rebound creates an income effect that increases real income which enables the consumer an opportunity to purchase an upgrade in quality, as well as an increase in demand (Wirl 1997, p. 20, 26-27, 31, 41, 197; Schipper and Grubb 2000; Saunders 2000b). In other words, as a resource becomes more efficient to use, and, therefore, more affordable, current technology will be used more or new technology will be introduced that contains more options and features. Even some traditional neoclassical models find that technologically enhanced labor and capital result in more consumption per worker (Saunders 1992, 2000b; Alcott 2005). In the next section, we build upon these findings by describing the data and models that will be used to empirically examine if there is any suggestion that Jevons' paradox exists for Europe, examining eighteen countries: Austria, Belgium, Bulgaria, Denmark, Finland, France, Germany, Greece, Hungary, Ireland, Italy, Netherlands, Norway, Portugal, Spain, Sweden, Switzerland, and the United Kingdom.

\section{DESCRIPTION OF DATA AND MODELS}

To obtain a complete understanding of the relationship between energy consumption and energy efficiency a macro level statistical analysis is necessary. The I=PAT model (Ehrlich and Holdren, 1971), described previously, will be used to determine the key variables in the models presented in this paper. Therefore, analyzing the environmental impact (I) will require examining the three main macro factors that influence energy consumption: (1) total population, rural and urban population, and population density (P), (2) gross domestic product and its components (A), and (3) energy intensity, a proxy for technological improvements (T). This type of calculation enables one to see which of the variables has the greatest impact on energy consumption. Table 1 presents the mapping of the variables used for analysis in this paper to the I=PAT equation. Data for the 1980 to 2004 time period was obtained from the Energy Information Administration's International Energy Annual.

Table 1: Mapping of Variables to the I=PAT Equation

\begin{tabular}{|c|c|c|c|}
\hline $\begin{array}{c}\text { Environmental Impact } \\
\text { (I) }\end{array}$ & $\begin{array}{c}\text { Population } \\
(\mathbf{P})\end{array}$ & $\begin{array}{c}\text { Affluence } \\
(\mathbf{A})\end{array}$ & $\begin{array}{c}\text { Technology } \\
(\mathbf{T})\end{array}$ \\
\hline Total Primary Energy Consumption & Population Density & Gross Domestic Product (GDP) & Energy Intensity \\
& Population & Exports \\
& Urban Population & Imports \\
& Rural Population & Household Consumption & \\
& & Government Consumption & \\
\hline
\end{tabular}

Total primary energy consumption, all energy that is consumed by end users plus losses that occur in the generation, transmission, and distribution, ${ }^{1}$ is employed as the measure of energy usage in each of the countries examined. Total population, rural and urban population, and population density are used to determine if population increases and urbanization are the major reason for increased energy use or not. GDP and its individual components (household consumption, government consumption, imports, and exports), in constant 2000 \$U.S., are a measure of economic activity and consumption of goods and services. GDP in constant 2000 international \$ (purchasing power parity) is also used to correct for any differences in exchange or inflation rates between countries. Energy intensity,

\footnotetext{
${ }^{1} \mathrm{http} / /$ www.eia.doe.gov/glossary/glossary_p.htm
} 
measured as BTU per constant 2000 \$ U.S. and in constant 2000 international \$, is used as a proxy for technological improvements that lead to improved energy efficiency. Each of these variables is used in the models described in the rest of the section.

Time-series cross-sectional (TSCS) regression models are used for analysis. TSCS data creates variability, thus eliminating heterogeneity, and provides more informative results by eliminating the need for lengthy time series by utilizing the information available on the dynamic reactions of each subject (Kennedy 2003). Furthermore, TSCS data permits both spatial and temporal effects to be examined, allowing a subject, in our case energy consumption, to be studied over multiple sites and observed over a defined time frame. Using time-series with crosssections can only enhance the quality and quantity of data that would be impossible using only one of these two dimensions (Gujarati 2003).

Therefore, TSCS is an invaluable tool. However, the regression estimates will likely be biased and inefficient. Several problems are frequent in TSCS analyses. First, errors tend to be serially correlated because observations and traits that characterize the error term tend to be interdependent across time. Second, the error terms tend to be correlated across countries. Third, heteroscedasticity is likely in TSCS data sets because the error variances tend not to be constant across countries. Fourth, the error terms may contain both spatial and temporal effects that produce a regression model with heteroscedastic and auto-correlated errors. The fifth and final problem that arises with TSCS analyses is that errors tend to reflect partial causal heterogeneity across time, space, or both (Hicks 1994).

In addition to the problems listed above, correlation in the data set is expected. To correct for these problems, maximum likelihood estimators are calculated by iterating the Generalized Least Squares method to correct for group-wise heteroscedasticity and correlation across groups, as well as group specific autocorrelation. Furthermore, if, as expected, correlation is present in the variables chosen for this study this technique provides unbiased estimators (Greene 2000). It is important to note that this technique does not produce a goodness-of-fit measure.

Variations of two generalized TSCS models, each described in the following passage, are used for analysis in this paper. These models, while simplistic, were chosen to capture as many macro-level effects that may be present as possible, enabling some insight to be obtained on how best to proceed on any future national, regional, or global energy policies. Unfortunately, there is little, if any, work on national/regional levels on Jevons' Paradox. Thus, the information obtained from these models will provide an important analysis of the existing energy policies in Europe and how well they are performing.

The first generalized model estimates energy consumption in relation to energy intensity, gross domestic product (constant 2000 \$US), and either population, urban and rural population, or population density.

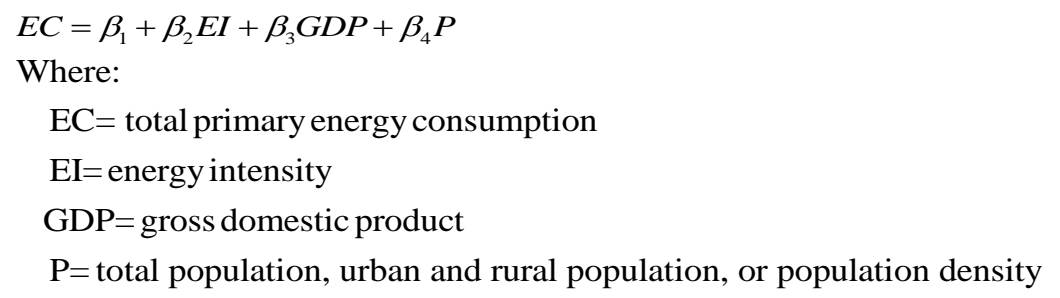

The first generalized model will provide supporting evidence for the macro-level manifestation of Jevons' Paradox if the coefficients for energy consumption and energy intensity are positive; indicating that energy consumption increases as energy intensity increases. The coefficients for both total primary energy consumption and energy intensity are expected to be positive. Additionally, the coefficients for GDP and population, urban and rural population, or population density are expected to be positive as well; as GDP increases so does energy consumption, and as population or population density increases so does energy consumption because there are more people. 
However, if energy intensity has the largest impact, then there is strong evidence that Jevons' paradox may exist. If energy intensity does not have the greatest impact on energy consumption then Jevons' paradox may be obscured or nonexistent as other variables may be responsible for the increased use of energy.

The second generalized model estimates energy consumption as a function of household consumption, government consumption, imports, exports, energy intensity, and either population, rural and urban population, or population density. In this model, GDP is disaggregated into its individual parts (household consumption, government consumption, imports, and exports) to determine which of the individual components impacts energy consumption; imports and exports are included to determine if international trade has an impact on energy consumption.

$E C=\beta_{1}+\beta_{2} E I+\beta_{3} H H+\beta_{4} G+\beta_{5} X+\beta_{6} M+\beta_{7} P$

Where:

$\mathrm{EC}=$ total primary energy consumption

EI=energy intensity

$\mathrm{HH}=$ household consumption

$\mathrm{G}=$ government consumption

$\mathrm{X}=$ exports

M=imports

$\mathrm{P}=$ population, urban and rural population, or population density

The signs of the coefficients for each of the variables in the second general model are expected to be positive, with the exception of imports. The coefficient for imports is expected to be either positive or negative.

Both generalized models are intended to specifically determine which variables have an impact on energy consumption. Furthermore, each of the models is used to provide some statistical evidence that Jevons' paradox may exist at the macro-level and to eliminate covariates of lesser importance. Both models are used to determine which factors, if there is some empirical evidence that Jevons' paradox may exist at the macro-level, drive the increased energy consumption. The results and findings of these models are discussed in the following section.

\section{RESULTS AND FINDINGS}

Each of the two models described above were tested for eighteen countries in the European Union: Austria, Belgium, Bulgaria, Denmark, Finland, France, Germany, Greece, Hungary, Ireland, Italy, Netherlands, Norway, Portugal, Spain, Sweden, Switzerland, and the United Kingdom. These countries were chosen because a complete data set from 1980-2004 was available. Other countries (Albania, Czech Republic, Poland, Romania, Slovakia, Turkey, and the former Yugoslavia) did not have a complete data set available and will be the subject of future research (see Polimeni and Polimeni, 2007a and 2007b).

As illustrated in Figure 1, each of the study countries exhibits an increase in energy consumption from 1980-2004 with the exceptions of Bulgaria, Hungary, and Germany which experienced a slight decrease in energy consumption. 
Figure 1: Total Primary Energy Consumption: 1980-2004

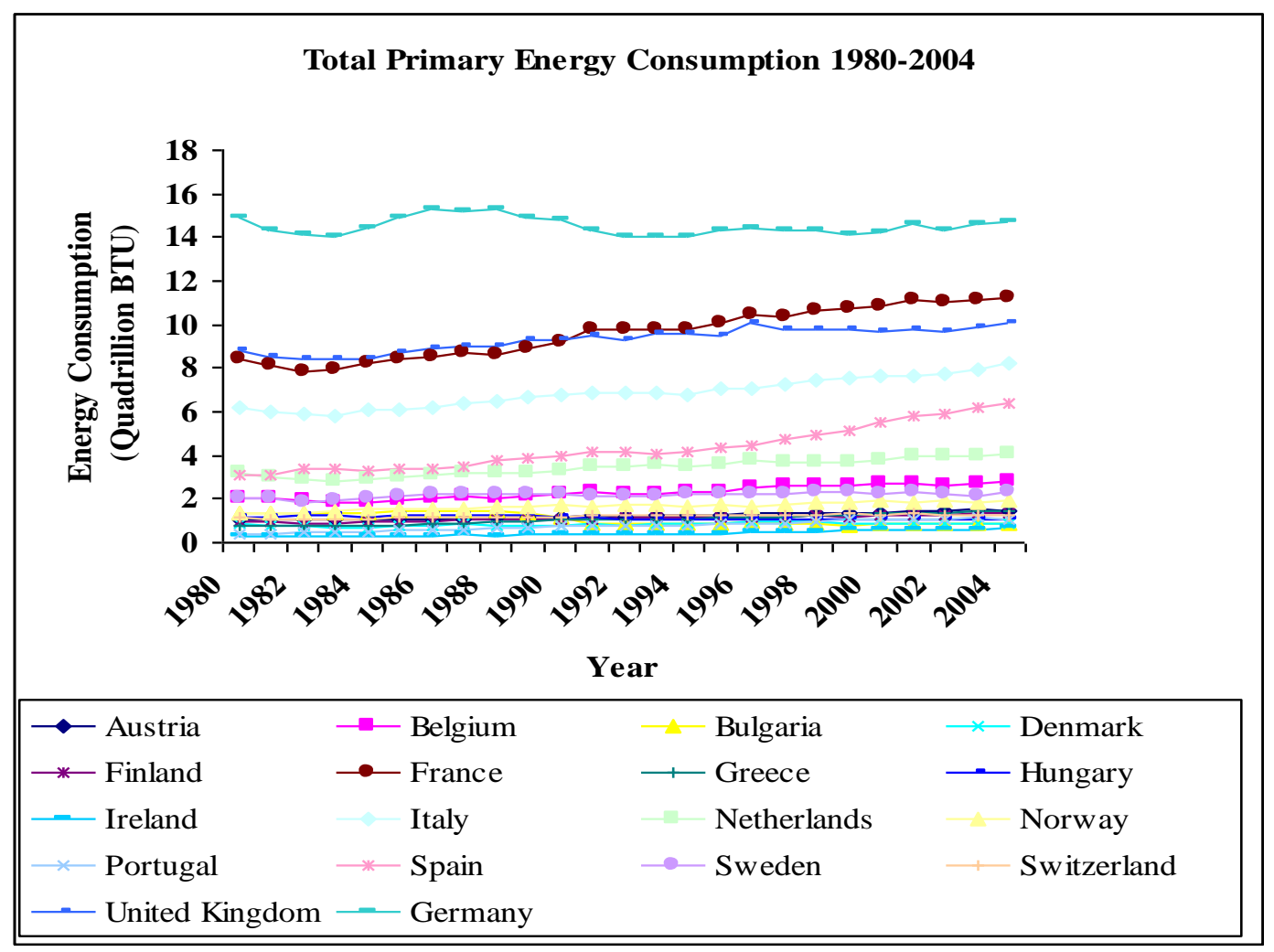

Additionally, as shown in Figure 2, each of the study countries experienced large decreases in energy intensity with the exception of Greece, Portugal, and Spain. Thus, a quick examination of the data illustrated above would lead one to conclude that Jevons' Paradox may exist for the selected eighteen countries of the European Union, as total primary energy consumption has increased at the same time that energy intensity decreased. However, further statistical analysis is needed to get a better understanding of which variables may affect total primary energy consumption the most.

Table 2 provides the results for Models 1, 2, and 3. Model 1 examines the relationship between total primary energy consumption and population, GDP (constant 2000 \$ U.S.), and energy intensity (BTU per constant 2000 \$ U.S.). Energy intensity has a positive coefficient, indicating that an increase in energy intensity causes increased energy consumption. Additionally, energy intensity has the coefficient with the greatest magnitude indicating that the impact of this variable is the greatest. The coefficients for population and GDP are also positive, as expected, indicating that as these variables increase, so does energy consumption. However, the magnitudes of these variables are much smaller than for the energy intensity variable suggesting that Jevons' paradox may exist. One should not be concerned by the small magnitudes of the coefficients, as the units of the variables are quadrillion BTU, millions of dollars, and millions of people. Thus, a small change in these variables can have a rather substantial impact on energy consumption. Model 2 examines the same relationship as Model 1 but measures GDP and energy intensity in purchasing power parity (constant 2000 international \$) instead of constant 2000 US \$. The reason for using purchasing power parity is to equalize the exchange rates of the eighteen countries studied to get a more accurate picture of their respective standards of living. The results show that there is little difference in the magnitude of the coefficients of the independent variables between the two models with the exception of energy intensity which nearly doubled. This outcome further supports the claim that Jevons' paradox may be in existence for the eighteen European Union countries. 
Figure 2: Energy Intensity: 1980-2004

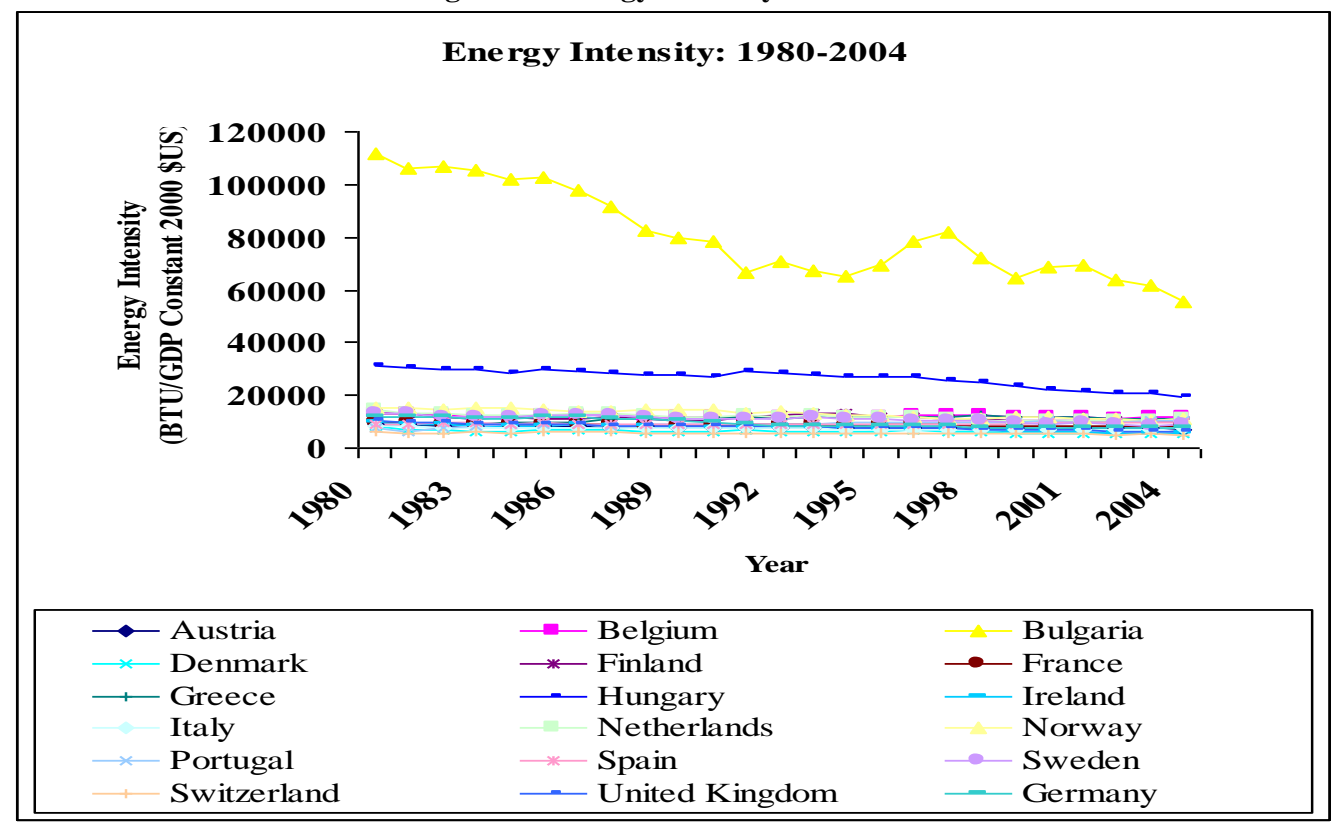

Table 2: Regression Results for Models 1, 2, and 3

\begin{tabular}{|c|c|c|c|}
\hline Variable & Model 1 & Model 2 & Model 3 \\
\hline \multirow[t]{3}{*}{ Constant } & -0.4216 & -0.713 & 0.0237 \\
\hline & $(0.0074)$ & $(0.0082)$ & $(0.0080)$ \\
\hline & {$[0.0000]$} & {$[0.0000]$} & {$[.0032]$} \\
\hline \multirow[t]{3}{*}{ Population } & 0.000000005 & 0.000000006 & -0.00000002 \\
\hline & $(0.0000)$ & $(0.0000)$ & $(0.0000)$ \\
\hline & {$[0.0000]$} & {$[0.0000]$} & {$[0.0000]$} \\
\hline \multirow[t]{3}{*}{ GDP (constant 2000 \$ US) } & $7 \mathrm{E}-12$ & & \\
\hline & $(0.0000)$ & & \\
\hline & {$[0.0000]$} & & \\
\hline \multirow[t]{3}{*}{ GDP (constant $2000 \$$ International) } & & $5 \mathrm{E}-12$ & \\
\hline & & $(0.0000)$ & \\
\hline & & {$[0.0000]$} & \\
\hline \multirow[t]{3}{*}{ Exports (constant 2000 \$ US) } & & & $3 \mathrm{E}-12$ \\
\hline & & & $(0.0000)$ \\
\hline & & & {$[0.0000]$} \\
\hline \multirow[t]{3}{*}{ Imports (constant 2000 \$ US) } & & & $-9 \mathrm{E}-13$ \\
\hline & & & $(0.0000)$ \\
\hline & & & {$[0.0000]$} \\
\hline \multirow[t]{3}{*}{ Household Consumption (constant 2000 \$ US) } & & & $6 \mathrm{E}-12$ \\
\hline & & & $(0.0000)$ \\
\hline & & & {$[0.0000]$} \\
\hline \multirow[t]{3}{*}{ Government Consumption (constant 2000 \$ US) } & & & $9 \mathrm{E}-12$ \\
\hline & & & $(0.0000)$ \\
\hline & & & {$[0.0000]$} \\
\hline \multirow[t]{3}{*}{ Energy Intensity (constant 2000 \$ US) } & 0.000066 & & 0.00005 \\
\hline & $(0.0000)$ & & $(0.0000)$ \\
\hline & {$[0.0000]$} & & {$[0.0000]$} \\
\hline \multirow[t]{3}{*}{ Energy Intensity (constant 2000 \$ International) } & & 0.00012 & \\
\hline & & $(0.0000)$ & \\
\hline & & {$[0.0000]$} & \\
\hline \multicolumn{4}{|l|}{ (Standard errors reported in parentheses) } \\
\hline [p-values presented in brackets] & & & \\
\hline
\end{tabular}


Model 3 extends the analysis further by decomposing GDP into its main components, household consumption, government consumption, exports, and imports, in order to determine which aspects of GDP have the greatest impact on energy consumption. The results further support the claim that Jevons' paradox may exist for Europe, with the coefficient for energy intensity the largest in magnitude of any of the variables and positive. Of the components of GDP, the exports variable has the largest coefficient which is positive, indicating that the eighteen European Union countries are exporting products which require a large amount of energy consumption during the production process. On the other hand, the imports variable has a negative coefficient implying that the eighteen European countries are importing products that consume less energy than the products the populace are currently using. The other components of GDP, household and government consumption are both significant, with positive coefficients. As anticipated, as these variables increase energy consumption does as well. The last variable of the model, population, surprisingly had a negative coefficient. The reason for this result is not immediately apparent and will require additional research. As shown in Table 3, models 4 through 6 extend the analysis further, determining if urbanization has an affect on total final energy consumption. Models 4 and 5 are similar, with the only difference that Model 5 measures GDP and energy intensity in purchasing power parity. The results indicate that population density has the greatest impact on energy consumption of any of the variables included in the two models. However, the coefficient of energy intensity is positive and the magnitude is only slightly less than that for population density, suggesting that Jevons' paradox may be in existence. There is very little difference in the coefficients for GDP in the two models. Model 6 takes the analysis further, replacing GDP with its main components. The findings show that energy intensity is the main factor increasing energy consumption. Additionally, as in Model 3, the coefficient for exports is positive and the coefficient for imports is negative. An interesting finding is that the sign of the coefficient for population density changed from positive in the previous two models to negative in Model 6. The reason for this sign change is unknown and is explored in Models 7 through 9.

Table 3: Regression Results for Models 4, 5, and 6

\begin{tabular}{|c|c|c|c|}
\hline Variable & Model 4 & Model 5 & Model 6 \\
\hline \multirow[t]{3}{*}{ Constant } & -0.4093 & -1.1854 & -0.7418 \\
\hline & $(0.0080)$ & $(0.0115)$ & $(0.0038)$ \\
\hline & {$[0.0000]$} & {$[0.0000]$} & {$[0.0000]$} \\
\hline \multirow[t]{3}{*}{ Population Density (people per square kilometer) } & 0.0002 & 0.00098 & -0.00009 \\
\hline & $(0.0000)$ & $(0.0000)$ & $(0.0000)$ \\
\hline & {$[0.0000]$} & {$[0.0000]$} & {$[0.0011]$} \\
\hline \multirow[t]{3}{*}{ GDP (constant 2000 \$ US) } & $8 \mathrm{E}-12$ & & \\
\hline & $(0.0000)$ & & \\
\hline & {$[0.0000]$} & & \\
\hline \multirow[t]{3}{*}{ GDP (constant 2000 \$ International) } & & $7 \mathrm{E}-12$ & \\
\hline & & $(0.0000)$ & \\
\hline & & {$[0.0000]$} & \\
\hline \multirow[t]{3}{*}{ Exports (constant 2000 \$ US) } & & & $3 \mathrm{E}-12$ \\
\hline & & & $(0.0000)$ \\
\hline & & & {$[0.0000]$} \\
\hline \multirow[t]{3}{*}{ Imports (constant 2000 \$ US) } & & & $-2 \mathrm{E}-12$ \\
\hline & & & $(0.0000)$ \\
\hline & & & {$[0.0000]$} \\
\hline \multirow[t]{3}{*}{ Household Consumption (constant 2000 \$ US) } & & & $1 \mathrm{E}-11$ \\
\hline & & & $(0.0000)$ \\
\hline & & & {$[0.0000]$} \\
\hline \multirow[t]{3}{*}{ Government Consumption (constant 2000 \$ US) } & & & $7 \mathrm{E}-12$ \\
\hline & & & $(0.0000)$ \\
\hline & & & {$[0.0000]$} \\
\hline \multirow[t]{3}{*}{ Energy Intensity (constant 2000 \$ US) } & 0.00006 & & 0.00007 \\
\hline & $(0.0000)$ & & $(0.0000)$ \\
\hline & {$[0.0000]$} & & {$[0.0000]$} \\
\hline \multirow[t]{3}{*}{ Energy Intensity (constant 2000 \$ International) } & & 0.00015 & \\
\hline & & $(0.0000)$ & \\
\hline & & {$[0.0000]$} & \\
\hline \multicolumn{4}{|l|}{ (Standard errors reported in parentheses) } \\
\hline [p-values presented in brackets] & & & \\
\hline
\end{tabular}


With the conflicting results for population density in Models 4 through 6, additional analysis is needed. Therefore, Models 7 through 9 decompose population into both urban and rural population to decipher how much of an influence urbanization has in Europe. Both variables are expected to have positive coefficients because, unlike many regions in the world, rural Europe has access to energy sources. Models 7 and 8 examine the relationship of GDP, both in 2000 \$ U.S. and in purchasing power parity terms, urban and rural population, and energy intensity to energy consumption. Once again the results suggest that Jevons' paradox may exist for the selected countries of the European Union, as energy intensity has the greatest magnitude of any of the coefficients in the models. As expected the coefficients for the other variables are all positive. One interesting result is that the urban population consumes energy two to three times more than the rural population. Slightly larger consumption was expected from the urban populace because the urban population in Europe is much greater than for rural regions ( $72 \%$ compared to $28 \%$ of the population) and industry is typically located in cities. The likely reasons for this narrow difference are the energy consumption requirements of the agricultural industry and the expansive public transportation system in European cities. Model 9 examines how the individual components of GDP, rural and urban population affect energy consumption. The results are similar to those of the previous models; the coefficient for imports is negative and the coefficients for the other variables are all positive and similar to magnitude to the results in Models 3 and 6. Therefore, the results of the models strongly suggest that Jevons' paradox may be in existence for the selected European Union countries.

Table 4: Regression Results for Models 7, 8, and 9

\begin{tabular}{|c|c|c|c|}
\hline Variable & Model 7 & Model 8 & Model 9 \\
\hline \multirow[t]{3}{*}{ Constant } & -0.5395 & -1.0912 & -0.7639 \\
\hline & $(0.0060)$ & $(0.0062)$ & $(0.0023)$ \\
\hline & {$[0.0000]$} & {$[0.0000]$} & {$[0.0000]$} \\
\hline \multirow[t]{3}{*}{ Urban Population } & 0.00000004 & 0.00000006 & 0.00000007 \\
\hline & $(0.0000)$ & $(0.0000)$ & $(0.0000)$ \\
\hline & {$[0.0000]$} & {$[0.0000]$} & {$[0.0000]$} \\
\hline \multirow{3}{*}{ Rural Population } & 0.000000003 & 0.00000002 & 0.00000003 \\
\hline & $(0.0000)$ & $(0.0000)$ & $(0.0000)$ \\
\hline & {$[0.0473]$} & {$[0.0000]$} & {$[0.0000]$} \\
\hline \multirow[t]{3}{*}{ GDP (constant 2000 \$ US) } & $7 \mathrm{E}-12$ & & \\
\hline & $(0.0000)$ & & \\
\hline & {$[0.0000]$} & & \\
\hline \multirow[t]{3}{*}{ GDP (constant 2000 \$ International) } & & $6 \mathrm{E}-12$ & \\
\hline & & $(0.0000)$ & \\
\hline & & {$[0.0000]$} & \\
\hline \multirow[t]{3}{*}{ Exports (constant 2000 \$ US) } & & & $5 \mathrm{E}-12$ \\
\hline & & & $(0.0000)$ \\
\hline & & & {$[0.0000]$} \\
\hline \multirow[t]{3}{*}{ Imports (constant 2000 \$ US) } & & & $-4 \mathrm{E}-12$ \\
\hline & & & $(0.0000)$ \\
\hline & & & {$[0.0000]$} \\
\hline \multirow[t]{3}{*}{ Household Consumption (constant 2000 \$ US) } & & & $9 \mathrm{E}-12$ \\
\hline & & & $(0.0000)$ \\
\hline & & & {$[0.0000]$} \\
\hline \multirow[t]{3}{*}{ Government Consumption (constant 2000 \$ US) } & & & $2 \mathrm{E}-12$ \\
\hline & & & $(0.0000)$ \\
\hline & & & {$[0.0000]$} \\
\hline \multirow[t]{3}{*}{ Energy Intensity (constant 2000 \$ US) } & 0.00006 & & 0.000076 \\
\hline & $(0.0000)$ & & $(0.0000)$ \\
\hline & {$[0.0000]$} & & {$[0.0000]$} \\
\hline \multirow[t]{3}{*}{ Energy Intensity (constant 2000 \$ International) } & & 0.00011 & \\
\hline & & $(0.0000)$ & \\
\hline & & {$[0.0000]$} & \\
\hline \multicolumn{4}{|l|}{ (Standard errors reported in parentheses) } \\
\hline [p-values presented in brackets] & & & \\
\hline
\end{tabular}




\section{DISCUSSION AND CONCLUSIONS}

Jevons' Paradox is of prime importance, especially considering current energy conditions and those that are projected for the future. Around the world, people have to contend with pollution from energy plants and occasional energy blackouts when energy demand spikes. Furthermore, energy prices are on a steady increase as the supply of natural resources that are used for energy production decreases and energy demand increases. However, policymakers, scientists, economists, and many others claim that new technological advancements, such as energy efficient appliances, will ease or solve any energy troubles that may arise.

However, this paper has presented empirical analysis that Jevons' Paradox may be in existence for the eighteen European Union countries at the macro-level. This is a significant finding given that Europe has consistently been a leader in attempting to reduce energy consumption and pollution. Consider some of the energy policies that the European Union has adopted. For example, the European Union has developed policy that all members must aim at achieving an energy savings of 9\% by 2012 through energy efficiency measures, and have created initiatives like the ManagEnergy Initiative and the Sustainable Energy Europe Campaign 2005-2008 (European Commission, 2007). Furthermore, new EU members are expected to reduce their energy intensity and energy consumption levels to those consistent with other member states. Therefore, one can conclude that policies promoting energy efficiency itself will likely not reduce energy consumption in Europe. Behavioral changes must accompany the public-policies that have been created to reduce energy consumption within the European Union.

The results of the regression results presented in this paper provide significant evidence that Jevons' paradox may exist for the eighteen European Union members. However, other findings provide some insight as well. Urban populations, as shown by the population density and urban population variables, consume more energy than people in rural areas. Therefore, European Union energy saving policies should be focused on urban users if energy consumption is to decrease. Another key finding is that imports reduce energy consumption, indicating that these imports are likely low energy consuming products such as clothing, oil, food, textiles, etc. This result suggests that the eighteen European Union countries may be exporting their pollution (i.e. energy intensive production) to lesser developed countries. The last key finding is that Jevons' paradox is likely not specific to just one sector or product as previous studies have indicated, but is economy-wide.

The micro details as to why these results suggest that Jevons' Paradox exists for the selected eighteen European Union countries are not discussed here because such an examination of the evolution of the structure of the regional and individual economies and societies will require a deep investigation of each of the study countries. Further research will attempt to answer these questions to fully comprehend the micro reasons for the possible existence of Jevons' paradox. This research will help identify the effects of national and regional energy policies so these energy strategies can be evaluated properly. The research presented in this paper makes an important contribution because the economy of the European Union, as with all economies, is dependent upon energy to produce goods and services. If, as projected, energy supplies tighten then European Union members will have to reverse the Jevons' paradox trend, otherwise a strong recession is likely. Therefore, further study is necessary to understand all the reasons for the potential existence of Jevons' paradox to avoid a potential economic slowdown.

\section{REFERENCES}

1. $\quad$ Alcott, B., 2005. Jevons' Paradox. Ecological Economics 54, 9-21.

2. Berkhout, P.H.G., Muskens, J.C., and Velthuijsen, J.W., 2000. Defining the Rebound Effect. Energy Policy 28, 425-432.

3. Birol, F. and Keppler, J.H., 2000. Prices, Technology Development and the Rebound Effect. Energy Policy 28, 457-469.

4. Boulding, K., 1949. Income or Welfare. The Review of Economic Studies XVII, 77-86.

5. $\quad$ Cherfas, J., 1991. Skeptics and Visionaries Examine Energy Saving. Science 25 1, 154-156.

6. $\quad$ Ehrlich, P.R. and Holdren, J.P., 1971. Impact of Population Growth. Science 171, 1212-1217.

7. European Commission, 2007. http://ec.europa.eu/energy/demand/index en.htm

8. Foster, J.B., 2000. Capitalism's Environmental Crisis - Is Technology the Answer? Monthly Review 52. 
9. Georgescu-Roegen, N., 1975. Energy and Economic Myths. Southern Economic Journal XLI, 347-381.

10. Giampietro, M., 1994. Using Hierarchy Theory to Explore the Concept of Sustainable Development. Futures 26, 616-625.

11. Greene, W.H., 2000. Econometric Analysis. $4^{\text {th }}$ Edition. Prentice Hall, Upper Saddle River, New Jersey.

12. Gujarati, D., 2003. Basic Econometrics. $4^{\text {th }}$ Edition. McGraw Hill, New York.

13. Haas, R. and Biermayr, P., 2000. The Rebound Effect for Space Heating: Empirical Evidence from Austria. Energy Policy 28, 403-410.

14. Hicks, A., 1994. Introduction to Pooling. In: T. Janoski and A. Hicks (Editors), The Comparative Political Economy of the Welfare State. Cambridge University Press, Cambridge, Massachusetts.

15. Jaccard, M. and Bataille, C., 2000. Estimating Future Elasticities of Substitution for the Rebound Effect. Energy Policy 28, 451-455.

16. Jevons, W.S., 1965. The Coal Question: An Inquiry Concerning the Progress of the Nation, and the Probable Exhaustion of Our Coal-Mines. $3^{\text {rd }}$ Edition revised by A.W. Flux, Augustus M. Kelley, New York.

17. Kennedy, P., 2003. A Guide to Econometrics. The MIT Press, Cambridge, Massachusetts.

18. Khazzoom, J.D., 1980. Economic Implications of Mandated Efficiency in Standards or Household Appliances. Energy Journal 1, 21-40.

19. Khazzoom, J.D., 1987. Energy Saving Resulting from the Adoption of More Efficient Appliances. Energy Journal 8, 85-89.

20. Laitner, J.A., 2000. Energy Efficiency: Rebounding to a Sound Analytical Perspective. Energy Policy 28, $471-475$.

21. Mayumi, K., 2001. The Origins of Ecological Economics: The Bioeconomics of Georgescu-Roegen. Routledge, London and New York.

22. Milne, G. and Boardman, B., 2000. Making Cold Homes Warmer: The Effect of Energy Efficiency Improvements in Low-income Homes. Energy Policy 28, 411-424.

23. Murray, M.P., 2006. Econometrics: A Modern Introduction. Pearson Addison-Wesley: Boston.

24. Newman, P., 1991. Greenhouse, Oil and Cities. Futures May, 335-348.

25. Polimeni, J.M. and R.I. Polimeni. (2007a). Energy Consumption in Transitional Economies (Part I): Jevons' Paradox for Romania, Bulgaria, Hungary, and Poland, Romanian Journal of Economic Forecasting, forthcoming.

26. Polimeni, R.I. and J.M. Polimeni. (2007b). Energy Consumption in Transitional Economies (Part II): Multi-scale Integrated Analysis of Societal Metabolism and Jevons' Paradox for Romania, Bulgaria, Hungary, and Poland, Romanian Journal of Economic Forecasting, forthcoming.

27. Princen, T., 1999. Consumption and Environment: Some Conceptual Issues. Ecological Economics 31, 347-363.

28. Roy, J., 2000. The Rebound Effect: Some Empirical Evidence from India. Energy Policy 28, $433-438$.

29. Saunders, H.D., 1992. The Khazzoom-Brookes Postulate and Neoclassical Growth. Energy Journal 13, 131-148.

30. Saunders, H.D., 2000a. Does Predicted Rebound Depend On Distinguishing Between Energy and Energy Services? Energy Policy 28, 497-500.

31. Saunders, H.D., 2000b. A View From the Macro Side: Rebound, Backfire and Khazzoom-Brookes. Energy Policy 28, 439-449.

32. Schipper, L. and Grubb, M., 2000. On the Rebound? Feedbacks Between Energy Intensities and Energy Uses in IEA Countries. Energy Policy 28, 367-388.

33. Schipper, L., Unander, F., Murthishaw, S., and Ting, M., 2001. Indicators of Energy Use and Carbon Emissions: Understanding the Energy-Economy Link. Annual Review of Energy and Environment 26, 4981.

34. Scott, A., 1980. The Economics of House Heating. Energy Economics 2, 130-141.

35. Velthuijsen, J.W. and Worrell, E., 2002. The Economics of Energy. In: J.C.J.M. van den Bergh (Editor), Handbook of Environmental and Resource Economics. Edward Elgar, Cheltenham, UK, pp. 177-194.

36. Wirl, F., 1997. The Economics of Conservation Programs. Kluwer Academic, Boston. 
International Business \& Economics Research Journal - October 2007

Volume 6, Number 10

NOTES 